\title{
“Professor, quero ser oprimida!": situação-limite e atos-limites no habitus professoral
}

\author{
Carlos Alberto Lopes de Sousa
}

Universidade de Brasília

\section{Resumo}

Esse artigo tem por objetivo apresentar e discutir episódio ocorrido no ensino superior em que estudante, tendo estudado a Pedagogia do Oprimido (Freire, 1987), demanda explicitamente a condição de ser oprimida pelo professor. 0 episódio registrado em diário de campo é analisado sob a ótica dos conceitos de situação-limite, inédito-viável, ambos de Paulo Freire (1992), e o de habitus, este último conceito de Bourdieu (1983). O conceito de habitus é posicionado no texto em perspectiva heurística, sendo denominado habitus professoral, nos termos de Silva (2003). 0 texto conclui que o pensamento freireano deve ser assumido como utopia sustentada no habitus professoral, expressando a negação do fugaz ou insatisfação momentânea e associado a movimento coletivo pela superação do estado das coisas e condições de existência desumanizadoras.

Palavras-chave: Habitus professoral. Bourdieu. Paulo Freire. Inédito-viável. Utopia. 


\section{Professor, I want to be oppressed!": limit-situations and limit-acts in e professorial habitus}

The goal of this article is to present and discuss an event occurred in a higher education environment, when a student, having studied Pedagogy of the Oppressed (Paulo Freire), explicitly demands to be oppressed by the professor. The episode, recorded in field notes, is analyzed from the perspective of the concepts of limit-situations and untested feasibility, both by Paulo Freire (1992), and Bourdieu's (1983) concept of habitus. The concept of habitus is employed in the text in a heuristic perspective, being expanded and qualified as professorial habitus, as defined in Silva (2003). The text concludes that Freire's thought should be adopted as a utopia sustained by the professorial habitus, expressing the negation of the fugacious or of fleeting dissatisfaction and associated with a collective movement for overcoming the state of things and dehumanized conditions of existence.

Keywords: Professorial habitus. Bourdieu. Paulo Freire. Untested feasibility. Utopia.

\section{Profesor, iquiero ser oprimida! : Situación límite y actos límites en habitus profesoral}

Este artículo tiene como objetivo presentar y discutir un hecho ocurrido en la educación superior en el que un estudiante, habiendo estudiado Pedagogía del Oprimido (Paulo Freire), exige explícitamente la condición de ser oprimida por el profesor. El episodio registrado en diario de campos y analiza desde la perspectiva de los conceptos de situaciones límite, inédito viable de Paulo Freire (1992) y de la concepción de habitus de Bourdieu (1983). El concepto de habitus es utilizado en una visión heurística, siendo ampliado y calificados como habitus profesoral, según Silva (2003). El texto concluye que el pensamiento de Freire debe asumirse en la utopía apoyada en el habitus profesoral que expresa la negación de la in satisfacción momentánea y fugaz, o asociado con el movimiento colectivo de superar el estado de cosas y las deshumanizador as condiciones de existencia.

Palabras clave: Habitusprofesoral. Bourdieu. Paulo Freire. Inédito viable. Utopía. 


\section{Introdução}

Paulo Freire alargou as nossas percepções de mundo, alimentando os desejos e iluminando a necessidade do desenvolvimento de uma pedagogia ética e utópica para a mudança social (Torres, 2003, p. 211). 0 projeto educativo de Paulo Freire é o da integração reconstrutiva da pedagogia do oprimido como uma pedagogia voltada para a descolonização do mundo (Torres, 2003, p. 206). Os argumentos e as imagens presentes nas narrativas de Paulo Freire também nos reconstituem pelo fato de não nos destinar a um lugar de observadores externos e nos provoca internamente, sacudindo conformismos e nos fazendo reconhecer nossos limites, tal qual afirma Linhares (2001, p.48): “[...] a incompletude de que somos feitos e a necessidade de recomeçar, reavaliando nossas organizações como estratégias para ir rompendo processos de submissão que nos aprisiona."

No campo dos estudos em sociologia da educação, o nome de Paulo Freire, junto com o de Illich', é citado como utópico ou profético (Gomes, 1994). Embora considere que seja utopia falar de sociedade igual, Demo (2004, 2004, p.19) ressalta a necessidade desse conceito negativo para combater tudo que existe e está aquém das nossas esperanças. Seguindo a tradição da Teoria Crítica, Demo (2004, p. 19) trata do conceito de utopia e utopismo. Critica o conceito de utopismo por ser integrante de uma dialética não antagônica, sendo um funcionalismo barato. Diz que é utopismo querer implantar na história pretensões absolutas como sociedade igual, expurgada de problemas sociais, estabelecendo como regra o tratamento igual a gente desigual, padronizações e estruturações de poder em que só resta ao dominado obedecer. Assim, a menção que o autor faz ao conceito de utopia, como tipicamente negativo, deve ser considerada na relação crítica ao conceito de utopismo. Acrescenta-se aqui, distintamente do horizonte do utopismo, a constatação de que as utopias diferem em seus conteúdos e funções, constituindo-se pelo sentido atribuído a elas por seu autor e a quem se destina. A utopia freireana mobilizou práticas educativas nos campos da educação popular, educação de jovens e adultos e em torno da perspectiva da escola pública popular.

A pedagogia freireana foi influenciada por matrizes teóricas advindas do pensamento humanista, inspirando-se no personalismo de Emmanuel Mounier, no existencialismo, na fenomenologia e no marxismo, sendo possível encontrar na estrutura do pensamento de Paulo Freire ecos dos trabalhos de Karl Marx, Antônio Gramsci, Weber, entre outros (Torres, 2003; Gadotti, 1989). Pode-se afirmar que o pensamento de Paulo Freire é heterodoxo e multirreferenciado, considerando suas fontes de inspiração. Nesse aspecto, Paulo Freire recebeu críticas por se

1. Illich foi um ex-padre católico que escreveu o livro Sociedade sem Escolas, defendendo entre outras ideias que a educação compulsória deveria ser abolida, sendo a escola uma organização custodial. 
afastar de teses marxistas ou pregar uma simples renovação da pedagogia nova. 0 pensamento de Paulo Freire conseguiu avançar no nível metódico, isto é, enquanto filosofia educacional que se faz prática educativa, que se reconstrói, à maneira dos círculos de cultura e enquanto perspectiva da relação entre seres no, com e do mundo. Nesse sentido, o pensamento utópico de Paulo Freire não se constitui utopismo, sendo prática efetivamente engendrada e testemunhada.

"Encontrei" Paulo Freire na década de 80, em meio às experiências coletivas que vivenciei no Movimento de Educação de Base - MEB. O MEB, criado na década de 60 , foi um movimento de grande amplitude em termos de alcance, e de forte ação local, principalmente no segmento da educação popular e educação de jovens e adultos. Os componentes pedagógicos e políticos do pensamento freireano se fizeram presentes na proposta educativa do MEB, embora com variações, intensidades e retrocessos, em face dos períodos históricos de turbulência experimentados por essa entidade à época de vigência da ditadura militar no Brasil, afetando também outros programas de educação popular criados na década de $60^{2}$.

0 nome de Paulo Freire esteve e ainda está presente em muitas iniciativas de educação popular e alfabetização de adultos - quando das críticas às pedagogias ditas bancárias e ao sistema educacional a serviço dos sistemas de dominação e opressão - e inspira processos educativos com ênfase em pedagogias voltadas à humanização e à transformação social. Cunha Filho (2003, p. 71) destaca que:

A quase redução do nome de Paulo Freire à temática da alfabetização de adultos foi, em grande parte, menos o resultado da leitura de suas obras e mais uma decorrência dos fatos que, no Brasil - período anterior ao Golpe - e no exílio, terminaram por envolvê-lo na problemática do analfabetismo adulto.

O chamado método Paulo Freire contribuiu para que esse educador se tornasse mundialmente conhecido e por quase escondero que havia de fundamental em sua proposta pedagógica, que é a concepção do conhecimento como uma construção dos sujeitos que interagem (Cunha Filho, 2003, p.71). A rigor, não se poderia falar em método Paulo Freire, pois este consiste em teoria do conhecimento e filosofia da educação (Gadotti, 1989, p. 32).

A contribuição do pensamento de Paulo Freire não se reduz à dimensão epistemológica da sua produção. As dimensões antropológicas e políticas também estão presentes. Cunha Filho (2003, p. 73) afirma que no pensamento de Paulo Freire a dimensão epistemológica se configura na visão do homem como ser

2. Para um estudo mais aprofundado destes programas, cf. PAIVA, Educação Popular e Educação de Adultos; GOÉS, De Pé no Chão também se aprende a Ler; CUNHA \& GÓES, O Golpe na Educação. Essas são apenas algumas referências importantes que tratam dos movimentos de educação e cultura popular na década de 60 . 
inacabado, mas que se sabe inacabado e, por isso, tem de se encontrar com os outros, sendo necessidade objetiva e exigência do processo criador. Para conquistar e transformar o mundo, os homens devem agir sobre ele e, a partir da ação que realizam, elaboram o conhecimento. 0 objeto do conhecimento é o mundo e a própria ação que realizam para conquistar o mundo, sendo o conhecimento fruto do encontro dos homens e de como interagem, sendo assim configurada a dimensão epistemológica no pensamento de Paulo Freire. Na dimensão política, o educador sustenta que ninguém pode conhecer-se como sujeito do ato, e as relações que são estabelecidas entre os homens podem afirmar ou negar essa condição.

Se tais relações tiverem como pressuposto que uns conhecem e outros ignoram, então os que sabem apresentam-se como sujeito do conhecimento, por isso devem oferecê-lo aos que não sabem. Daí resulta: os que sabem, pensam e ordenam, e os que não sabem apenas obedecem. É neste sentido que o encontro dos homens viabiliza, na história, a desumanização. Mas a tarefa que o inacabamento reclama dos homens é a humanização. Esta só pode realizar-se na medida em que os homens todos são reconhecidos como sujeitos do ato de conhecer. Este pressuposto exige que as relações estejam apoiadas no diálogo. (Cunha Filho, 2003, p.73).

As dimensões de análise e compreensão do pensamento de Paulo Freire avançam também para os aspectos éticos e estéticos. Todas as dimensões podem ser vistas de forma entrelaçadas, como parte do processo de crítica, autocrítica, autonomia, conscientização e humanização voltadas para a transformação social.

Linhares (2001, p. 47) afirma que Paulo Freire exerce com maestria a construção de drenagens e canalizações por onde faz fluir memórias suas e nossas, e essas vão enfraquecendo os mecanismos de opressão, não só por denunciá-los, mas evidenciando como funcionam os mecanismos de produção e manutenção da opressão, convidando-nos a fazê-lo, atentando para a sua precariedade histórica, seus vazios, rachaduras e contradições.

A criança tem o hábito de fazer certas perguntas que nos deixam boquiabertos, perplexos, diante de questões realizadas numa simplicidade e espontaneidade detentoras de uma força que nos incomoda, nos desequilibra, nos faz pensar na resposta ou não resposta. Na profissão de professor ${ }^{3}$ há vertentes pedagógicas que proclamam que o docente deve construir possibilidades de abertura às problematizações dos alunos. Por outro lado, como valorizar as perguntas dos alunos quando o próprio professor não faz as suas próprias perguntas? Portanto, cair na imobilidade do perguntar e de trilhar diálogos com o outro - interlocutores ou textos -, consigo mesmo e com a natureza abre espaço à colonização de

3. Para este texto, optei por utilizar indistintamente as expressões professor, educador, aluno, estudante, educando. 
esquemas de pensamento que paralisam a ação criativa e inovadora. Colonização que ocorre quando não nos abrimos para pensar sobre o vivido e o concebido. Cada pessoa adulta deve fazer um esforço para retomar dentro de si a criança inquiridora.

No contexto dessa reflexão, tomo como referência as situações-limites encontradas no ensinar e aprender em sala de aula, em perspectiva freireana. Quais são as perguntas inquiridoras e mobilizadoras para essa reflexão?

Em diálogo com o pensamento freireano, e considerando o habitus professoral, como se caracteriza a situação-limite e o potencial para o inédito-viável nos atos estabelecidos na relação professor e aluno? 0 pensamento freireano é algo concretizável em sala de aula ou este pode apenas ser assumido como pensamento utópico? Este artigo tem por objetivo apresentar e analisar episódio na prática educativa docente em que a possibilidade do inédito-viável se evidencia em atos-limites no habitus professoral. Os atos-limites ocorrem inseridos em situações-limites, sendo aqui pontuados tanto os elementos do mundo social quanto o sentido da ação pedagógica em sala de aula. 0 episódio apresentado foi extraído de diário de campo, isto é, registros das anotações pessoais das aulasde Sociologia da Educação, quando do debate de temas e questões vinculadas ao pensamento freireano. O episódio se apresenta como "disparador" de outros episódios que possam provocar o estudo e a pesquisa do pensamento freireano em sala de aula.

O conceito freireano do "inédito-viável" e o desafio da reconstrução do habitus professoral em situações práticas também são expostos e discutidos no texto. Em relação ao conceito geral de habitus, estabelece-se diálogo com o pensamento do sociólogo francês Pierre Bourdieu. Esse conceito será situado, especificamente e principalmente, enquanto discussão no que se refere ao habitus professoral nos termos de Silva (2003). De forma geral, o conceito bourdieusiano assumido neste texto parte da perspectiva de reconstrução das tramas sociais, sem atribuir a único fator a causa determinante das práticas educativas, por exemplo. Os fatores materiais, culturais e sociais, entre outros, formam o espaço social concreto de compreensão de dado fenômeno social. Pelo exposto, não se tem aqui a pretensão de investigar as causas que determinam a relação entre os atos e a situaçãolimite, mas a lógica que penetra em sua manifestação.

0 artigo se desenvolve numa orientação em que não há um sujeito que escreve sobre um objeto que the é estranho. Aliás, aqui reside a concepção de um sujeito que reflete sobre o próprio sujeito e as interações estabelecidas e registradas diante de outros, em face das situações discursivas e práticas que defronta no campo da atuação. Nessa perspectiva é que se segue a orientação epistemológica com base na reflexividade reflexa de Bourdieu (2007). O conceito de reflexividade reflexa funda-se num "olho" sociológico para perceber e controlar no campo da pesquisa os efeitos da estrutura social no contexto das formações discursivas (Bourdieu, 2007, p. 694). A reflexividade reflexa acontece na postura do autor em 
construir o discurso, situando-o em algumas referências do mundo social que objetiva a realidade e, ao mesmo tempo, subjetivamente produz sentidos. Tanto em termos conceituais, no caso do habitus, quanto na abordagem da reflexividade, a pretensão heurística estará presente.

\section{0 inédito-viável e as situações-limites}

Nas "Notas" finais apresentadas no livro Pedagogia da Esperança (Freire, 1992), escritas por Ana Maria Araújo Freire (Nita Freire) ${ }^{4}$, esta autora destaca o conceito do inédito-viável do autor, enfatizando que homens e mulheres encontram nas suas vidas pessoal e social obstáculos que precisam ser vencidos, sendo esses denominados "situações-limites". Ana Maria Freire diz nas "Notas" que diante das situações-limites há várias atitudes dos sujeitos envolvidos. Uma das atitudes consiste em identificar queas situações-limites não podem ser transpostas, ou identificá-las como algo que não se quer transpor. Outra atitude é reconhecer que a situação-limite existe e precisa ser rompida, então há empenho em sua superação. 0 termo "situações-limites" foi utilizado por Freire a partir da contribuição de Álvaro Vieira Pinto, que, por sua vez, o extraiu de Jaspers, esvaziando-o da dimensão pessimista original (Nita Freire, 2009, p. 231).

As ações necessárias para romper as "situações-limites" são denominadas por Paulo Freire de "atos limites". Vale destacar que as situações-limites não podem ser vistas e analisadas sem considerar a dimensão macrossociológica e a especificamente espaço-temporal de desenvolvimento da ação educativa e pedagógica.

As situações-limites implicam, pois, a existência daqueles e daquelas a quem diretamente servem, os dominantes; e daqueles e daquelas a quem se "negam" e se "freiam" as coisas, os oprimidos.

Os primeiros vêem os temas-problemas encobertos pelas "situações-limites" daí os considerar como determinantes históricos e que nada há a fazer, só se adaptar a elas. Os segundo quando percebem claramente que os temas desafiadores da sociedade não estão encobertos pelas 'situações-limites' quando passam a ser um 'percebidodestacado', se sentem mobilizados a agir e a descobrirem o "nédito-viável".'(Nita Freire, 2009, p. 205-206, grifo do autorl

Mas o que define o inédito-viável enquanto pedagogia? Nita Freire (2009) diz

4. Ana Maria Araújo Freire também assina trabalhos publicados com o nome Nita Freire. Por isso, este artigo faz referência aos nomes Ana Maria Araújo Freire e Nita Freire. No artigo da autora citado neste texto, correspondente ao ano de 2009, há o registro dos dois nomes. Optei pelo uso do nome Nita Freire quando da citação referente ao texto de 2009. 
que o conceito de inédito-viável foi criado a partir das influências que Paulo Freire recebeu de André Nicolai por meio da categoria "soluções possíveis despercebidas" e de Lucien Goldman com a de "consciência possível". Nita Freire (2009, p.231) diz ainda que o inédito-viável não é a simples junção de letras ou expressão, mas sim palavração, práxis, como possibilidade de transformar o mundo. Assim, o inéditoviável é "palavra na qual estão intrínsecos o dever e o gosto de mudarmos a nós mesmos dialeticamente mudando o mundo e sendo por este mudado" (Nita Freire, 2009, p. 231).

A pedagogia do inédito-viável mobiliza o sujeito para refletir sobre a visão da história como possibilidades, e não como algo fatalista, já determinado e insuperável. Desta forma, a realidade é concebida como algo que está sendo e pode ser transformado.

Conforme sugere Freitas (2005), há quatro movimentos complementares em relação à vivência do inédito-viável como espaço de práticas, vivência:

(1) proposição do inédito - trata-se do convite à reflexão através da vivência de 'pôr a mão na massa', bem como dos movimentos que precedem sua realização - é o momento do acolhimento e da problematização inicial; (2) mão na massa -caracteriza-se pela vivência da feitura do pão em si, constituída por quatro movimentos mobilizadores da reflexão na ação - as primeiras reações, preparar a massa, sovar e modelar; (3) sistematização da reflexão - refere-se à proposição de potencializar os momentos de espera e cuidado - crescer e assar a massa até o pão ficar pronto - mediante a elaboração da reflexão sobre a ação através de relatórios em grupos, e; (4) hora da partilha - consiste no momento coletivo de partilha da reflexão sobre a reflexão na ação - gerada na vivência e a partir dela - mediante a apresentação dos relatórios dos grupos. A hora da partilha é também o momento de celebração dos resultados da feitura do pão, com a sua degustação. (Freitas, 2005, p. 8).

Tanto no espaço escolar quanto no não escolar, desenvolvem-se inúmeras ações pedagógicas em situações-limites, tendo seus atos limites. Mas essas situaçõeslimites terão sentido enquanto olhar e intervenção na perspectiva do inédito-viável e direcionamento para a construção dos processos educativos emancipatórios. Daí, então, que localizar as problematizações iniciais no contexto do inédito-viável é um primeiro movimento importante para posicionar a questão na realidade do processo pedagógico do ensinar-aprender em qualquer espaço educativo.

\section{0 habitus e o habitus professoral}

Habitus é um conceito importante no pensamento de Pierre Bourdieu. Esse conceito se originou de Aristóteles pelo nome de hexis, que significa uma disposição, "um estado adquirido e firmemente estabelecido do caráter moral que orienta 
os nossos sentimentos e desejos numa situação e, como tal, a nossa conduta." (Wacquant, s.d., p.1).

Bourdieu (1983, p.94) define habitus como

[...] sistema de disposições adquiridas pela aprendizagem implícita ou explícita que funciona como um sistema de esquemas geradores, é gerador de estratégias que podem ser objetivamente afins aos interesses objetivos de seus autores sem terem sido expressamente concebidas para este fim.

Bourdieu utiliza o conceito de habitus para designar disposições duráveis nos indivíduos geradas a partir da mediação entre o exterior e o interior, a sociedade e o indivíduo. Dessa forma, o habitus se constitui por um conjunto de disposições no indivíduo originadas a partir da sua relação com o meio social. Essas "disposições duráveis", ou "capacidades treinadas" e "propensões estruturadas" é que configuram a conduta de cada um perante as demandas da sociedade (Wacquant, s.d., p. 2).

As reflexões de Bourdieu sobre o habitus nos convocam à reflexão crítica, lembrando-nos que as propriedades que se associam às categorias estão ligadas ao mundo do conhecimento prático dos indivíduos no mundo e por isso são, necessariamente, contextuais e sociais (Fornel, 2005, p. 228-229).

Atento à perspectiva da reflexividade reflexa, tomo como referência que o conceito de habitus não deve ser reificado como "coisa" dada e que determinada ação possa ser imediatamente compreendida pelo simples a priori conceitual. Sem dúvida, o conceito orienta a leitura e a intervenção na realidade, mas o confronto com a realidade pode fazer emergir novos conceitos. Bourdieu propõe que a prática não é o precipitado mecânico de ditames estruturais e nem o resultado da perseguição intencional de objetivos pelos indivíduos, mas antes

o produto de uma relação dialética entre a situação e o habitus, entendido como um sistema de disposições duráveis e transponíveis que, integrando todas as experiências passadas, funcionando em cada momento como uma matriz de percepções, apreciações e acções e torna possível cumprir tarefas infinitamente diferenciadas, graças à transferência analógica de esquemas [sic]. (Bourdieuapud Wacquant, s. d., p. 2-3)

0 habitus - mais adiante situado como habitus professoral - reforça, (re)produz e se atualiza espacial e temporalmente em práticas educativas desenvolvidas em estruturas as mais diversas - econômicas, políticas, sociais, culturais, simbólicas e de linguagem --, devendo ser objeto constante da nossa curiosidade, autocrítica e capacidade de recriar-se subjetivamente, reconstruindo-se teimosamente, para melhor agir no mundo.

A elaboração do conceito de habitus professoral nos termos de Silva (2003) tem sua fonte não só em Bourdieu mas sobretudo em sua experiência educativa tanto da formação inicial quanto para a docência. 
Silva (2003) analisou memórias e experiências de professores, em consonância com o aporte conceitual de Valter Benjamin, Bourdieu e E. P. Thompson. Em Benjamin, entre as várias ideias que Silva (2003, p. 11) destaca está a de que ouvir experiências vividas por outras pessoas é um ato generoso e, acrescenta a autora, também humano e que está em desuso. Em Thompson, a autora destaca que o conhecimento produzido na vida prática não deve ser desprezado e a "apreensão desse tipo de saber é forjada no jogo que se estabelece entre o aporte conceitual e os dados empíricos e exige o mesmo rigor científico presente nos estudos eminentemente teóricos (...)" (Silva, 2003, p.12).Partindo de Bourdieu, Silva (2003, p. 12, grifo no originall afirma que o "habitus é constituído ao longo de nossa vida e suas características"dependem daquilo que vimos, ouvimos, praticamos e reproduzimos com as informações advindas das representações que constituímos sobre as coisas".

A experiência utilizada como instrumento metodológico permite compreender "os modos pelos quais os sujeitos efetivam, historicamente, as práticas sociais" (Silva, 2005, p. 34).Silva (2005) diz que a experiência permite uma maior aproximação da realidade, já que ela se origina de vivências concretas e complexas, devendo-se levar em consideração que as experiências de cada um são significadas por meio das representações. Estas contam ao mesmo tempo com elementos mentais e recursos do mundo vivido. As práticas educativas devem ser tanto objeto e conteúdo da nossa curiosidade e sistematização quanto aposta na sua possibilidade de reconstrução.

Para colocar em prática uma educação que respeite a compreensão do mundo dos educandos, desafiando-os a pensar criticamente, e que não separe o ensino do conteúdo, exige-se formação permanente dos educadores e educadoras,

[...] mas sobretudo, exige um empenho sério e coerente no sentido da superação das velhas marcas autoritárias, elitistas, que perduram nas pessoas em que elas "habitam" sempre dispostas a ser reativadas. E sem o exercício dessa tentativa de superação, que envolve a nossa subjetividade e que implica o reconhecimento de sua importância, tão menosprezada e minimizada pelo dogmatismo que a reduz a mero reflexo da objetividade, toda tentativa de mudança da escola para pô-la numa direção democrática, tende a não vingar. (Freire, 1992, p. 168-169).

Embora sem se utilizar do conceito de habitus, Paulo Freire afirma ideia nessa direção, ao dizer:

Às vezes, nós é que não percebemos o 'parentesco' entre os tempos vividos e perdemos assim a possibilidade de 'soldar' conhecimentos desligados e, ao fazê-lo, iluminar com os segundos, a precária claridade dos primeiros. (Freire, 1992, p. 19).

Nos espaços-tempos vividos manifestam-se conscientemente ou inconscientemente as influências da formação escolar e familiar, por exemplo. As nossas 
práticas educativas representam uma das oportunidades do estabelecimento das ligações entre o fruto das influências das estruturas do mundo social e a nossa subjetividade. 0 pensamento pedagógico de Paulo Freire é marcado pela seriedade crítica, pela objetividade humanística e pela subjetividade engajada, sempre aliadas e presentes em suas obras ${ }^{5}$.

Assume-se neste artigo que "a natureza do ensino na sala de aula é constituída por uma estrutura estável, porém estruturante, isto é, uma estrutura estável mas não estática, que denominamos habitus professoral" (Silva, 2005, p. 153, grifo no original).

\section{“Professor, quero ser oprimida!"}

0 episódio a seguir evidencia a vivência concreta e complexa no ensinar e aprender em perspectiva freireana. Encontrava-me junto aos alunos no último encontro de discussões sobre o livro Pedagogia do Oprimido (Freire,1987). Os estudantes eram oriundos de vários cursos acadêmicos e com uma média de 21 anos de idade. Entre os temas em aprofundamento estava o medo da liberdade de que se faz objeto o oprimido, mas que também se instala de modo diferente nos opressores. Paulo Freire afirma que, nos oprimidos, o medo da liberdade é o medo de assumi-la, sendo que estes introjetam a sombra dos opressores e seguem suas pautas. Os oprimidos, à medida que expulsam a sombra dos opressores, deverão preencher o vazio, estabelecendo suas pautas, seus conteúdos e assim exercendo a autonomia com responsabilidade.

Concluídos o estudo e o debate em torno das ideias do livro de Paulo Freire - e estando este autor/professor mobilizado pela perspectiva de que os estudantes assumissem a sua autonomia, elegendo livremente para o trabalho final da disciplina temas ou questões relacionadas aos autores discutidos em sala de aula, entre esses Paulo Freire -, uma aluna levantou a mão e dirigiu-se a mim dizendo: "Professor, eu quero ser oprimida! Diga-me o tema ou questão que devo desenvolver. Não quero escolher o meu tema livremente!" De imediato, a intervenção da aluna tornou-se um obstáculo a ser vencido em uma situaçãolimite. Pensei: “Como é possível essa afirmação categórica após a discussão do livro Pedagogia do Oprimido?"

Diante da situação e perante a turma, o habitus professoral acionou esquema gerador constituído dos seguintes atos, a saber: a intervenção, a devolução e os

5. A expressão "objetividade humanística e subjetividade” engajada consta no livro de Freire (1992). 
encaminhamentos ${ }^{6}$, sendo partes da estratégia geral de "sustentação da problematização" como algo a ser conhecido e aprofundado a partir da experiência.

Cada elemento do esquema gerador realizou-se:

1) intervindo, transitando entre o apelo à autoridade moral do professor pelo discurso do sentido da atividade para que os alunos saíssem da "sombra do professor" e estruturando algumas problematizações para que os estudantes também fizessem as suas perguntas e levantassem as suas hipóteses. Para tanto, a pergunta da aluna foi devolvida aos estudantes da seguinte forma: como cada um retomaria em situaçãode docência a questão da estudante, elegendo como ponto de partida a experiência de ensinar e aprender em Paulo Freire em sala de aula? Complementarmente, foram realizadas duas outras problematizações: quais as questões que o grupo faria em relação à interrogação da aluna? Quais as hipóteses do grupo para explicar o fato de a aluna solicitar ser oprimida?

2) devolvendo, sob forma de estruturação do conteúdo - situação vivenciada em sala de aula e texto de Freire -, o tema da autonomia e autoria na construção do conhecimento e de como a liberdade de escolha repercute na formação dos estudantes, acrescentando ainda a indispensável presença do professor no processo de orientação dos trabalhos e da relação entre os estudantes.

3) encaminhando agendamento de encontro específico com a aluna, escutandoa em relação à sua própria questão e ao exercício da sua liberdade, sem espaço para licenciosidade ou autoritarismo docente e retomando, coletivamente, 0 assunto da aula?

A devolução da sistematização das questões à turma teve como resposta alguns minutos de silêncio. Uma das hipóteses para o apelo da estudante era que, por ter a oportunidade de exercitar a liberdade, seria arriscado exercê-la, julgando que talvez o professor não fosse gostar do tema, elaborando algo que poderia acarretar nota ruim. A opção pela escolha do tema ou questão seria arriscada. Seria mais seguro "pedir" um tema ao professor. Nesse aspecto há algo presente: o poder do professor. Há uma questão de poder emergente na relação porque o educando se espelha no poder da autoridade do professor. Quem fala o quê e sobre o quê, e em quais circunstâncias?

6. Participei nos anos 90 de curso de formação promovido pelo MEB e ministrado por Madalena Freire. Nesse curso as etapas da intervenção, devolução e encaminhamento foram tanto praticadas quanto houve aprofundamento conceitual. Essas etapas foram resgatadas do meu aprendizado conceitual e do aprofundamento da discussão pedagógica.

7. Em aula subsequente, cada estudante socializou o seu tema e as questões de estudo e pesquisa, discutindo-os com o restante da turma. 
0 tipo de postura da estudante é condizente com aquela interpretação de Charlot (2009, p. 95), quando este afirma que os alunos foram desapropriados e desapropriaram a si mesmos do sentido do que fazem: avaliam o trabalho como algo chato e aborrecido e dão valor apenas à nota que obtêm do trabalho submetido ao crivo do professor. Operou no habitus professoral um duplo movimento tensionante: i) o movimento de realizar atos e estratégias de trabalho em sala de aula para que os estudantes conhecessem e aprofundassem o pensamento de Paulo Freire a partir da perspectiva teórica e crítica e ii) o movimento de tomar a demanda da aluna como conteúdo e experiência para vivenciar, coletiva e criticamente, a Pedagogia do Oprimido em sala de aula, problematizando a demanda da aluna pelo tema e projetando a reorientação das aulas planejadas e desenvolvidas até então. Vale frisar que, nesse segundo movimento, resurgia a influência das experiências no MEB no campo da educação popular e educação de pessoas jovens e adultas, idealizando para aquela situação a constituição de uma espécie de círculo de cultura freireano no espaço acadêmico, por meio do qual emergiriam os temas e as questões geradoras de leitura e estudo.

Esses movimentos ampliavam o aprender em perspectiva freireana, considerando as relações com o mundo, mas as situações-limites se impunham objetivamente e subjetivamente no habitus professoral, envolvendo tanto a percepção do mundo social quanto as práticas e o sentido dessas inseridas no cotidiano do trabalho docente.

No mundo social, os sujeitos lutam pela sobrevivência e buscam o ideal da "prosperidade" por diversas vias lobter certificação; buscar formação continuada, cursos e trabalhos rápidos "para não pensar muito"; terminar o curso para fazer concurso público o mais rápido possível). Nesse mundo caótico, que foge à capacidade de controle, o "conhecer" cria problemas complexos e mal definidos, provocando situações problemáticas não só no ensinar e no aprender; para além disso, repercute na própria condição biopsicossocial do sujeito (depressão, doenças relacionadas ao trabalhol e promove a reafirmação de teses perversas e globais do mundo social - uma boa epítome desta constatação é a sentença "Time is money!".

Os atos pedagógicos em sala podem se configurar como burocráticos, caracterizando-se pela centralidade e exposição erudita do docente apenas. Vale esclarecer que a exposição erudita do professor não se constitui problema em si. 0 problema reside no fato de o estudante não ser provocado a sair da sombra do professor. 0 professor se apega à ideia do programa a cumprir, à reclamação em torno da leitura dos textos pelos alunos, a questões curriculares, entre outros aspectos, para abrigar o lote de inseguranças na relação entre professor e aluno, muitas vezes não assumido.

No episódio relatado, a pedagogia freireana operou no ato-limite da educação problematizadora, destacando-se o aprofundamento da relação autoridade e liberdade no ensinar e aprender em sala de aula, contextualizando, ampliando o 
conteúdo, entendido como também aquele da relação que mobilizou a participação na discussão. Assim, ir além da educação problematizadora, constituindo e estendendo o inédito-viável, era a possibilidade de radicalmente alterar e experimentar Freire, não em uma ou duas aulas, mas em toda e qualquer aula, mudando a concepção das aulas historicamente construídas e reproduzidas socialmente no ambiente acadêmico até então.

A utopia se alimenta do reconhecimento de uma ordem não vivenciada no espaço de ensino e aprendizagem, sendo a condição desejável das aulas. Todavia, o inédito-viável se constituiu, não pela perspectiva das aulas "imaginadas" que queria o docente, mas nos atos-limites da experiência vivida e na visão da maioria dos alunos de que é possível posicionar o habitus professoral em um campo de relações distintas daquelas orientadas para o silenciamento dos estudantes, sendo essa categoria mediadora da relação entre as condições de existência no mundo social e a prática educativa e pedagógica desencadeada.

As problematizações, intervenções e devoluções sistematizadas da discussão, instrumentos para desvelar algumas minúcias da relação do tipo opressora, provocaram os estudantes a preencher o vazio do silêncio coletivo que se formou no momento imediato àquele em que se levantou originalmente a questão em sala de aula. No pensamento originário de Bourdieu, o habitus é concebido no horizonte das descobertas dos implícitos presentes nos mecanismos de construção e reprodução social, não sendo preocupação desse autor o enfoque no trabalho ou na atividade escolar e seu potencial enquanto desdobramento na ação dos alunos. 0 projeto de uma pedagogia racional que tudo fizesse para neutralizar de forma sistemática a ação dos fatores sociais de desigualdade cultural foi abandonado no trabalho intelectual de Bourdieu. Vale salientar que, enquanto o pensamento de Bourdieu tem acento predominantemente cético em relação à escola, o de Freire expressa a esperança e a utopia sustentada. Daí a opção heurística pelo conceito de habitus, sendo a última visão a inspirar-me no trabalho educativo.

Pode-se afirmar que o pensamento freireano é aplicável em sala de aula, mas não como um ditame inflexível em termos de relação educativa, tendo perspectiva causal e determinística nas relações no ensinar e aprender. A relação educativa em perspectiva freireana desloca o professor da sua zona de conforto, gera tensão, mas também acarreta o anúncio de um futuro por vir, exercendo sem dúvida nenhuma a vocação humanizadora de educar. Essa vocação humanizadora não pode confundir-se com práticas educativas espontaneístas, licenciosas ou que se fingem democráticas ou ainda sustentadas na ideia de diálogo que se supõe um blá-blá-blá, solto, sem bom senso e rigorosidade metódica. Em termos de pensamento freireano utópico, o habitus professoral em sala aula manifesta a tensão entre o anúncio de um presente que não concretiza a utopia e nem se pode esgotar no trabalho ou atividade escolar, por mais que seja "inteligentemente orientada".

Notadamente, o ato-limite tem o seu limite à medida que se faz restrito a uma 
reflexividade individual da experiência do pensar criticamente e experimentada episodicamente em atividades pedagógicas em sala de aula.

A herança da reflexividade em alunos e professores é a memória da experiência, quando significativa para uns. Essa memória pode ter sua extensão e ressignificação nos espaços coletivos de engajamento, luta e transformação do mundo social, indo além da experiência em si de desvelar o mundo, mas tendo desdobramento em termos de participação em um campo mais amplo das relações sociais.

Compartilho da visão de que é importante levar em consideração que a análise que envolve a interação entre as práticas e os seus conteúdos, entre sistema, estrutura e cotidiano deve consistir numa descrição minuciosa dos processos internos em sala de aula, sendo que esta não invalidará teses mais globais em relação ao sistema e contribuirá para matizá-las e para delimitar as mediações pelas quais a escola reproduz a desigualdade social e cultural (Perrenoud, 2001, p. 64).

\section{Considerações finais}

Pode-se afirmar, de forma geral, que o inédito-viável é conceito mobilizador que nos ajuda a compreender criticamente as contradições que derivam das experiências ou vivências realizadas no campo educacional e pedagógico no espaço tanto escolar quanto não escolar, ajudando-nos na elaboração de um projeto de mudança e transformação da realidade. A contradição não é só categoria interpretativa do real, mas ela própria existente no movimento do real, como motor interno do movimento, já que se refere ao curso do desenvolvimento da realidade (Cury, 1979, p. 30).

A relação em torno de ensinar e aprender é marcada pelos valores que nos orientam e que dão a configuração do fenômeno educativo do qual fazemos parte e no qual somos sujeitos ativos, à medida que realizamos intervenções. A história que se incorpora nas estruturas é aquela que se incorpora no nosso corpo, no nosso habitus professoral nos atos-limites.

Há tanto contradições quanto obstáculos nos atos de ensinar e aprender no conteúdo da relação emergente no habitus professoral. Há também a negação no enfrentamento da realidade no ensinar e aprender, trazendo consequências tal qual a interdição do professor na sua capacidade de reconstruir-se diante da prática já incorporada no seu cotidiano los mesmos textos, as mesmas atividades, as mesmas avaliações, a mesma estrutura de relação, as mesmas piadas e exemplos) e daquela sedimentada no não desafio feito ao educando para sair da sombra do professor.

Dar-se conta disso, assumir e ter mecanismos para operar esse aprendizado contínuo é desafiador na prática educativa. Quantas falas, textos, intervenções dos alunos e do professor já foram tão ricas, e foram perdidas na memória enquanto 
perspectiva da construção do conhecimento? Quantas oportunidades são perdidas em conhecer e provocar a saída dos alunos da sombra do professor? Conhecer o aluno não se restringe à identificação de um perfil, pois esse não é o quem vai atuar. Quem irá atuar será o sujeito aprendiz, e não o perfil de aluno que se tem. Isso pelo fato de que muitas vezes o perfil tem mais elementos - idealizados, é bem verdade - do que o próprio sujeito identificado na realidade concreta.

A utopia freireana não é algo que deva ser tomado como fugaz, uma insatisfação momentânea, mas algo que deve ser assumido com entusiasmo, otimismo, uma esperança sustentada em relação à superação do estado das coisas, das condições de existência desumanizadoras, que aponta para um projeto societário humano, ético, solidário, igualitário e democrático. Entre a utopia e a sua realização existe um tempo histórico que é o tempo da ação transformadora (Diana Cunha, s. d. apud Bellanova, 1996, p. 604). Particularmente, entendo que no espaço e tempo da sala de aula há o potencial para engendrar algumas transformações, mesmo não impactando e alterando substantivamente as estruturas do mundo social. Nesse espaço em potencial se encontram as situações-limites e se desenvolvem os atoslimites fundados em uma utopia e otimismo sustentado.

Algo reconhecido como complexo exige muitas inteligências engajadas, agindo coletivamente. Só assim o recuo ideológico no conhecimento da realidade pode ser superado, rompendo o que aprisiona o sujeito. Por fim, "o educador não é aquele que simplesmente forma, mas ao formar está se formando e ao mesmo tempo re-forma cotidianamente o seu processo de formação (Emerenciano; Lopes de Sousa; Freitas, 2001, p. 8).

\section{Referências}

BELLANOVA, Bartolomeu. Educação e utopia em Paulo Freire: o verdadeiro realismo do devir humano. In: GADOTTI, Moacir. Paulo Freire: uma biobibliografia. São Paulo :Editora Cortez, 1996. p. 603-606.

BOURDIEU, Pierre. Questões de sociologia.Rio de Janeiro: Marco Zero, 1983.

. A miséria do mundo. 6. ed. Petrópolis, RJ : Vozes, 2007.

CHARLOT, Bernard. A escola e o trabalho dos alunos. Revista de Ciências da Educação, n. 10, set./dez. 2009. p. 89-95.

CUNHA, Luiz Antônio, GOÉS, Moacir de. 0 golpe na educação. 7.ed. Rio de Janeiro: Jorge Zahar Editor, 1991.

CUNHA FILHO, José Leão da. A palavra geradora: uma aproximação entre Freire e Piaget. Brasília: Editora Universa, 2003.

CURY, Carlos Alberto Jamil. Educação e contradição: elementos metodológicos para uma teoria crítica do fenômeno educativo. 4.ed. São Paulo: Cortez: Autores Associados, 1989. 
DEMO, Pedro. Sociologia da educação: sociedade e suas oportunidades. Brasília: Plano Editora, 2004.

EMERENCIANO, M. do Socorro Jordão; LOPES DE SOUSA, Carlos Alberto; FREITAS, Lêda Gonçalves de. Ser presença como educador, professor e tutor. Colabora, Curitiba, ago. 2001. Disponível em:<http://gemini.ricesu.com.br/colabora/n1/ index1.htm>. Acesso em: 20 jan. 2012. (Revista Digital da CVA - RICESU)

FORNEL, Michel de. Habitus e etnométodos. In. ENCREVÉ, Pierre; LAGRAVE, RoseMarie (Coord). Trabalhar com Bourdieu. Rio de Janeiro: Bertrand Brasil, 2005. p. 221-229.

FREITAS, Ana Lúcia Sousa de. Pedagogia do inédito viável. Contribuições de Paulo Freire para fortalecer o potencial emancipatório das relações ensinar-aprenderpesquisar. V Colóquio Internacional Paulo Freire - Recife, 19 a 22set. 2005.

FREIRE, Paulo. Pedagogia do oprimido. Rio de Janeiro : Paz e Terra, 1987. .Pedagogia da esperança: um reencontro com a pedagogia do oprimido. Notas: Ana Maria Araújo Freire. Rio de Janeiro: Paz e Terra, 1992.

. Seminário de Metodologia. Instituto Cajamar. Departamento de Formação. 04 de abr. de 1988. Debate com Paulo Freire. Documento em meio impresso.

FREIRE, Nita. Inédito-viável. In: STRECK, Danilo R.; REDIN, Euclides; ZITKOSKI, Jaime José (Orgs). Dicionário Paulo Freire. 2. ed. Belo Horizonte : Autêntica Editora, 2009. p. 231-234. Verbete.

FREITAS, Lêda Gonçalves de; CUNHA FILHO, José Leão; LOPES DE SOUSA, Carlos Alberto; MARIZ, Ricardo Spindola. Reconstrução das práticas docentes: uma estratégia de para a formação de professores a partir da prática. In: FREITAS, Lêda Gonçalves de; MARIZ, Ricardo Spindola; CUNHA FILHO, José Leão (Orgs.). Educação superior: princípios, finalidades e formação continuada de professores. Brasília: Editora Universa, 2010, p. 149-165.

GADOTI, Moacir. Convite à leitura de Paulo Freire. São Paulo: Editora Scipione, 1989.

GÓES, Moacir de. De pé no chão também se aprender a ler, 1961-1964: uma escola democrática. 2.ed. São Paulo: Cortez, 1991.

GOMES, Cândido Alberto. A educação em perspectiva sociológica. 3.ed. São Paulo: EPU, 1994.

LINHARES, Célia. Memórias como narrações compartilhadas. FREIRE, Ana Maria (Org). In: A Pedagogia da libertação em Paulo Freire. São Paulo : Editora UNESP, 2001.

PAIVA, Vanilda. Educação popular e educação de adultos. 5.ed. São Paulo: Loyola, 1987.

PERRENOUD, Philippe. A pedagogia na escola das diferenças: fragmentos de uma sociologia do fracasso. Porto Alegre: Artmed, 2001.

SILVA, Marilda. Como se ensina e como se aprende a ser professor: A evidência dohabitus professoral e da natureza prática da didática. Bauru, SP: EDUSC, 2003. . 0 habitus professoral: o objeto dos estudossobre o ato de ensinar na sala 
de aula. Revista Brasileira de Educação, São Paulo, n. 29, 152-163, maio/ jun/ jul/ ago. 2005. Disponível em: <http://www.scielo.br/>. Acesso em: 11 jan. 2012.

TORRES, Carlos Alberto (Org). Teoria crítica e sociologia política da educação. São Paulo: Cortez Editora: Instituto Paulo Freire, 2003.

WACQUANT, L. Esclarecer o Habitus.New School for Social Research.

Disponível em:<http://sociology.berkeley.edu/faculty/wacquant/wacquant_pdf/ ESCLARECEROHABITUS.pdf>. Acesso em: 11 jan. 2012.

Recebido em abril de 2012

Aprovado em julho de 2012

Carlos Alberto Lopes de Sousa é doutor em Sociologia pela Pontifícia Universidade Católica de São Paulo. Atualmente é professor de Sociologia da Educação no Departamento Teoria e Fundamentos da Universidade de Brasília na Faculdade de Educação e do Programa de Pós-Graduação em Educação, tendo como interesse as seguintes temáticas: habitus, diferença e cultura no ensinar e aprender, classes populares e médias e educação a distância, socialização pela internet, ongs e educação. Email:carloslopesđuunb.br 